\title{
Identification of Potential Inhibitors of Severe Acute Respiratory Syndrome-Related Coronavirus 2 (SARS-CoV-2) Main Protease from Non-Natural and Natural Sources: A Molecular Docking Study
}

\author{
Osvaldo A. Santos-Filho ${ }^{\circledR * a}$ \\ ${ }^{a}$ Laboratório de Modelagem Molecular e Biologia Estrutural Computacional, \\ Instituto de Pesquisas de Produtos Naturais Walter Mors, Centro de Ciências da Saúde, \\ Universidade Federal do Rio de Janeiro, Bloco H, Cidade Universitária, \\ 21941-902 Rio de Janeiro-RJ, Brazil
}

\begin{abstract}
So far, there is neither a vaccine nor a specific antiviral drug to prevent or treat COVID-19 (coronavirus disease) infection. Recent studies have been done to investigate the capacity of human immunodeficiency virus type 1 (HIV-1) protease inhibitors be used in the treatment of COVID-19 patients. Some of those drugs have shown to be promising. Natural chemical substances from plants provide a good source of chemicals for the development of potential novel antiviral drugs against viral pathogens including HIV-1. In January 2020, a new promising target useful for structure-based drug design was elucidated and stored in the Protein Data Bank. In this context, the objective of this study was to determine whether and how a set of both non-natural and natural HIV-1 protease inhibitors could dock to that novel crystallized severe acute respiratory syndromerelated coronavirus 2 (SARS-CoV-2) main protease and, consequently, to identify potential lead compounds to treat COVID-19 infected patients. The results showed that two non-natural compounds, danoprevir and lopinavir, and one compound from plant, corilagin, produced strong interactions with the inhibitor binding site of SARS-CoV-2 main protease. It is expected that this work contributes to validate the use of HIV-1 protease inhibitors against SARS-CoV-2.
\end{abstract}

Keywords: molecular docking, coronavirus, COVID-19, protease, natural products

\section{Introduction}

Coronaviruses (CoVs) are a large family of viruses which may cause illness in animals and humans. Those viruses are known to cause respiratory infections ranging from the common cold to more severe diseases like severe acute respiratory syndrome (SARS). ${ }^{1}$ At the end of December 2019, a novel CoV of severe acute respiratory syndrome-related coronavirus 2 (SARS-CoV-2) was identified to be the cause of pneumonia outbreak in China, named COVID-19. ${ }^{2}$ This disease is less deadly but much more infectious than common SARS. ${ }^{1}$ Until May 25, $5,304,772$ people have been infected with the disease, and 342,029 deaths were reported worldwide. ${ }^{1}$

The main symptoms of COVID-19 disease are fever, tiredness, and dry cough. Some patients may have aches and pains, nasal congestion, runny nose, sore throat, and diarrhea. Around 1 out of every 6 people who gets

*e-mail: osvaldo@ippn.ufrj.br
COVID-19 becomes seriously ill and develops difficulty breathing. Elderly people and person with pre-existing medical conditions like high blood pressure, heart diseases, lung diseases, cancer or diabetes are more likely to develop serious illness. ${ }^{1}$

To date, there is neither a vaccine nor a specific antiviral drug to prevent or treat the disease. ${ }^{1}$ Previous studies were carried out to investigate the ability of human immunodeficiency virus type 1 (HIV-1) protease inhibitors be used for the treatment of COVID-19 patients. ${ }^{3}$ Moreover, a new survey by Genetic Engineering \& Biotechnology News (GEN) reveals 35 active drug development programs to fight against COVID-19, which have received public attention in recent days in North America, Europe, and China. ${ }^{4}$ Those known drugs including HIV-1 protease inhibitors, such as danoprevir (1), darunavir (2), lopinavir (3), oseltamivir (4), and ritonavir (5) have received considerable attention (Figure 1). ${ }^{4}$

Natural products provide a good source of chemicals for the development of potential novel antiviral drugs 


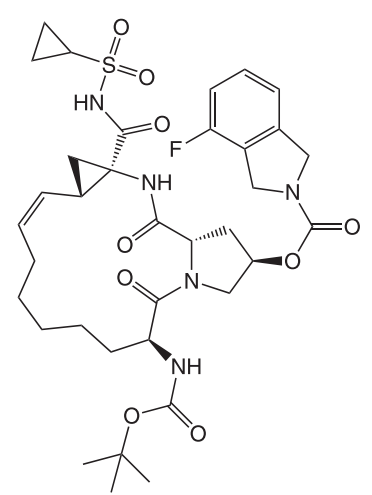

1<smiles>CC(C)CN(CC(Cc1ccccc1)NC(=O)OC1COC2OCCC12)S(=O)(=O)c1ccc(N)cc1</smiles>

2<smiles>CC(C)c1nc(CN(C)C(=O)N[C@H](C(=O)N[C@@H](Cc2ccccc2)C[C@H](O)[C@H](O)Cc2ccccc2)C(C)C)cs1</smiles>

5<smiles>CC(C)c1cc2c(c(O)c1O)C1(C(=O)O)CCCC(C)(C)C1CC2</smiles>

6<smiles>Cc1cccc(C)c1OCC(=O)N[C@@H](O)[C@H](Cc1ccccc1)NC(=O)[C@H](C(C)C)N1CCCNC1=O</smiles>

3

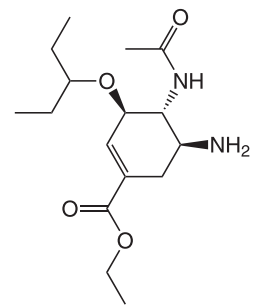

4<smiles>O=c1c(O)c(-c2ccc(O)cc2)oc2cc(O)cc(O)c12</smiles>

8<smiles>COc1cc2oc3cc(O)c(CC=C(C)C)c(O)c3c(=O)c2c(O)c1CC=C(C)C</smiles>

9<smiles>CC(C)=CCCc1c(O)c(O)cc2oc3cc(O)c(CC=C(C)C)c(O)c3c(=O)c12</smiles>

10

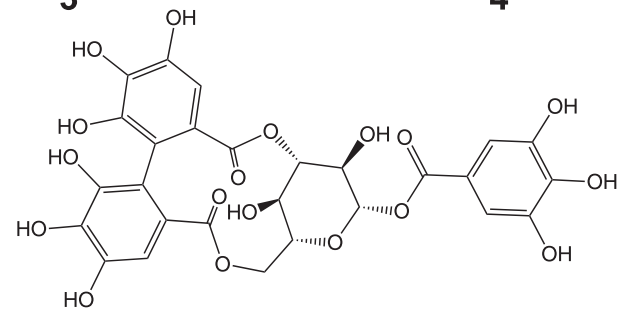

7

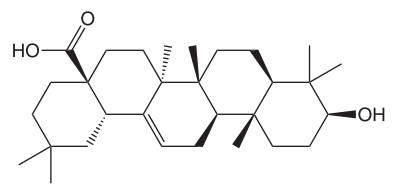

11

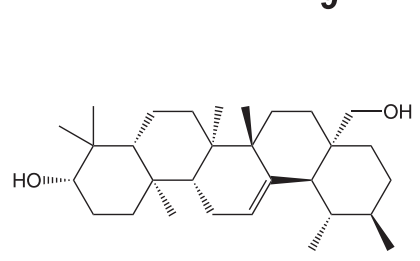

12

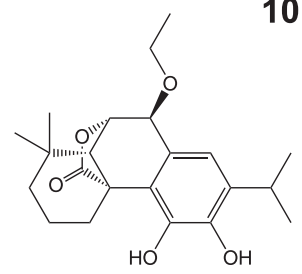

13

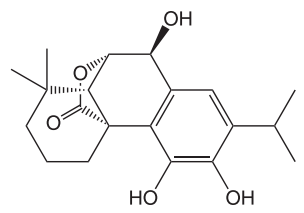

14<smiles>Cc1cc(C(=O)N[C@@H](C)C(=O)N[C@H](C(=O)N[C@@H](CC(C)C)C(=O)N[C@H](CCC(=O)OCc2ccccc2)Cc2cc[nH]c2O)C(C)C)no1</smiles>

15

Figure 1. Non-natural-HIV-1 protease inhibitors; HIV-1 protease inhibitors from plants; and $N$-[(5-methylisoxazol-3-yl)carbonyl]alanyl-L-valyl$N \sim 1 \sim-((1 R, 2 Z)-4-($ benzyloxy)-4-oxo-1- $\{[(3 R)$-2-oxopyrrolidin-3-yl]methyl $\}$ but-2-enyl)-L-leucinamide.

against viral pathogens such as coronavirus, dengue virus, hepatitis $\mathrm{B}$ and $\mathrm{C}$ virus, herpes simplex virus, influenza virus, and human immunodeficiency virus. ${ }^{5}$ Polya $^{6}$ published a review regarding protein and non-protein inhibitors from plants, which included potent HIV-1 protease inhibitors (Table 1, and Figure 1).

Coronaviruses contain a genome composed of a long ribonucleic acid (RNA) strand, which acts just like a messenger RNA when it infects a cell and directs the synthesis of two long polyproteins that include the machinery that the virus needs to replicate new viruses. These proteins include a replication/transcription complex that makes more RNA, several structural proteins that construct new virions, and two proteases. The proteases play essential roles in cutting the polyproteins into all of these functional pieces. In January 26, 2020, Liu and coworkers ${ }^{15}$ deposited the crystal structure of SARS-CoV-2 main protease $\left(\mathrm{M}^{\mathrm{pro}}\right)$ in complex with an inhibitor 
Table 1. HIV-1 protease inhibitors from plant

\begin{tabular}{|c|c|c|c|}
\hline \multirow{2}{*}{ Compound (class) } & \multirow{2}{*}{ Plant source } & HIV-1 specificity & \multirow{2}{*}{ Reference } \\
\hline & & $\mathrm{IC}_{50} / \mu \mathrm{M}$ & \\
\hline Carnosolic acid (6) (abietane diterpene) & Rosmarinus officinalis (Lamiaceae) & 0.2 & 7 \\
\hline Corilagin (7) (hydrolysable tannin) & Phyllanthus amarus (Euphorbiaceae) & 21 & 8 \\
\hline Kaempferol (8) (flavonol) & $\begin{array}{c}\text { widespread; Cuscuta reflexa (Convolvulaceae), } \\
\text { Pisum sativum (Fabaceae) }\end{array}$ & 7 & $8-10$ \\
\hline$\alpha$-Mangostin (9) (prenylated xanthone) & Garcinia mangostana (Clusiaceae) & 5 & 11,12 \\
\hline$\gamma$-Mangostin (10) (prenylated xanthone) & Garcinia mangostana (Clusiaceae) & 5 & 11 \\
\hline Oleanolic acid (11) (oleanene triterpene) & $\begin{array}{l}\text { Luffa cylindrica (Cucurbitaceae), } \\
\text { Rosmarinus officinalis (Lamiaceae) }\end{array}$ & $8 ; 22$ & 13 \\
\hline Uvaol (12) (usrsene triterpene) & Crataegus pinnatifida (Rosaceae) & 6 & 14 \\
\hline 7- $O$-Ethylrosmanol (13) (abietane diterpene) & semi-synthetic from carnosolic acid & 5 & 7 \\
\hline Rosmanol (14) (abietane diterpene) & semi-synthetic from carnosolic acid & 2 & 7 \\
\hline
\end{tabular}

HIV-1: human immunodeficiency virus type $1 ; \mathrm{IC}_{50}$ : half maximal inhibitory concentration.

( $N$-[(5-methylisoxazol-3-yl)carbonyl]alanyl-L-valyl- $N \sim 1 \sim-$ $((1 R, 2 Z)-4$-(benzyloxy)-4-oxo-1-\{[(3R)-2-oxopyrrolidin3-yl]methyl \}but-2-enyl)-L-leucinamide) (15; Figure 1) in the Protein Data Bank (PDB ID: 6LU7). That crystal structure is currently the only public-domain 3D structure from SARS-CoV-2, and it is organized as a dimer of two identical subunits that together form two active sites (Figure 2). Such a protease is thought to be a promising target for discovery of small-molecule drugs that would inhibit the cleavage of the viral polyprotein and prevent the spread of the infection. ${ }^{15}$

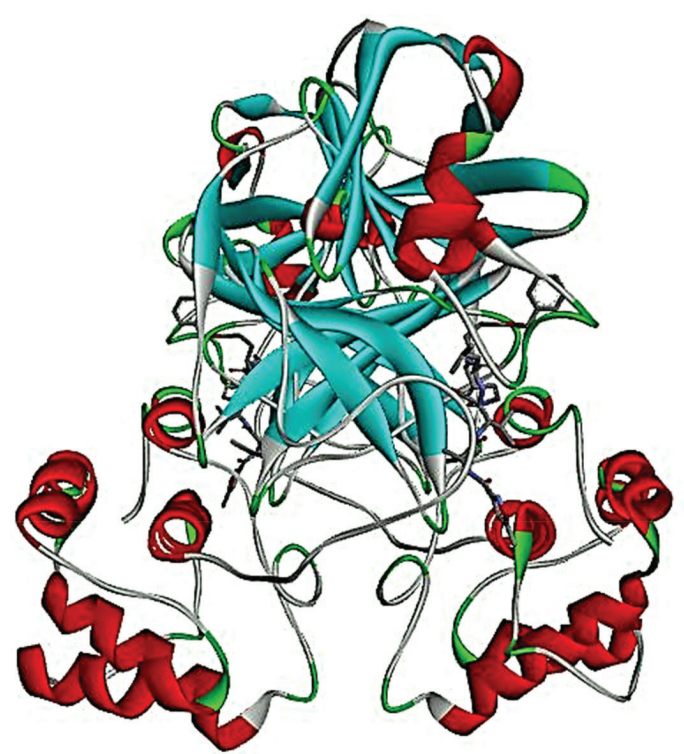

Figure 2. SARS-CoV-2 $\mathrm{M}^{\text {pro }}$ in complex with $\mathrm{N} 3$ inhibitor (adapted from PDB ID: 6LU7). ${ }^{15}$

To investigate the possibility that non-natural and natural HIV-1 protease inhibitors may interact with the SARS-CoV-2
$\mathrm{M}^{\mathrm{pro}}$ and, consequently, identify potential inhibitors of this enzyme, a molecular docking study was performed.

\section{Methodology}

The crystallographic structure of SARS-CoV-2 $\mathrm{M}^{\text {pro }}$ (PDB ID: 6LU7) ${ }^{15}$ was used as the biomacromolecular receptor in molecular docking simulations. The threedimensional structures of both non-natural and natural HIV-1 protease inhibitors were obtained from PubChem. ${ }^{16}$ Those structures were energy minimized using the universal force field molecular mechanics method. ${ }^{17}$ The molecular docking simulations were performed with AutoDock Vina 1.1.2 software. ${ }^{18}$ Molecular graphic representations were performed with PoseView 1.1.2, ${ }^{19}$ PyMOL 2.1.0, ${ }^{20}$ and BIOVIA Discovery Studio $2020^{21}$ softwares.

\section{Results and Discussion}

In order to develop a molecular docking protocol, the inhibitor that is co-crystallized with the SARS-CoV-2 $\mathrm{M}^{\text {pro }}$ structure, 15, was redocked in its binding cavity. Default parameters of the docking software were used, except the exhaustiveness that was defined as 50. Figure 3 shows that $\mathbf{1 5}$ was satisfactorily redocked and, consequently, all subsequent docking simulations were performed according to the same protocol.

According to the results of the molecular docking simulations, HIV-1 protease inhibitors interact strongly with the SARS-CoV-2 M $\mathrm{M}^{\text {pro. }}$. Table 2 shows the results of the calculated inhibitors-protease interaction affinities, as well as the key interacting binding site residues of the SARS-CoV-2 $\mathrm{M}^{\mathrm{pro}}$. 
(a)

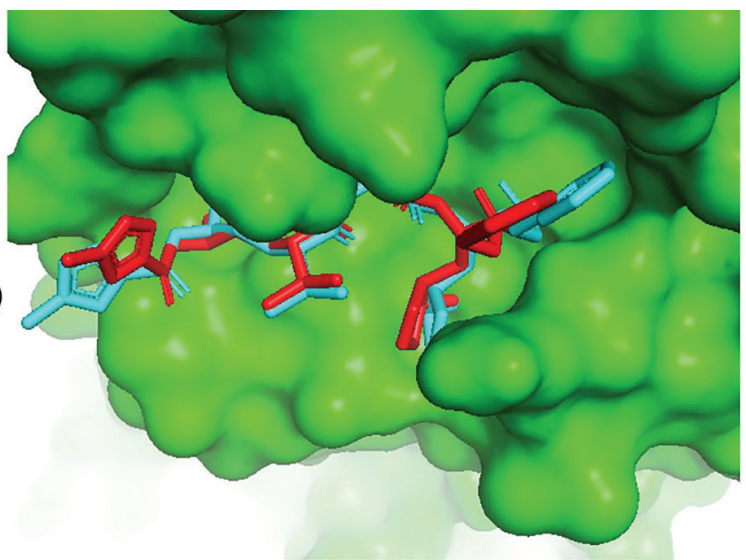

(b)

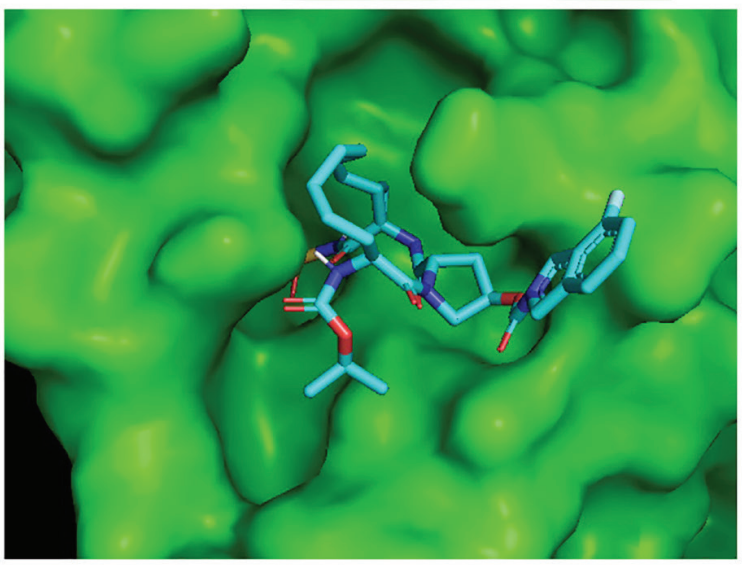

(c)

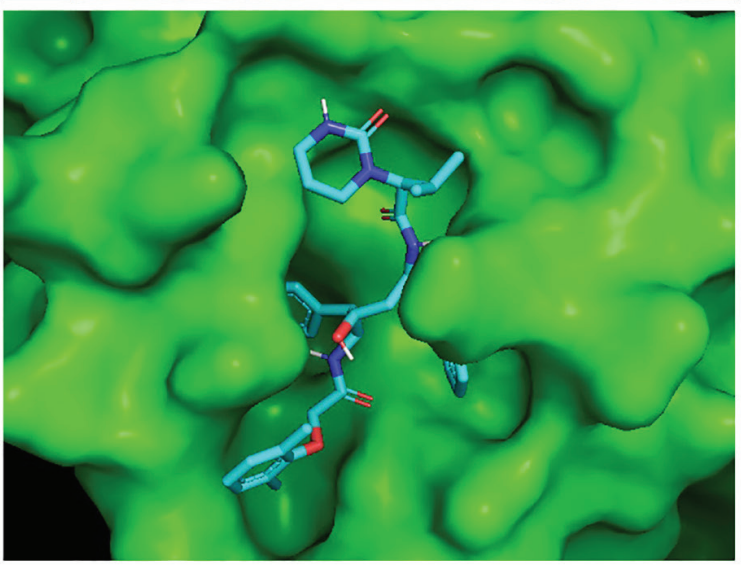

(d)

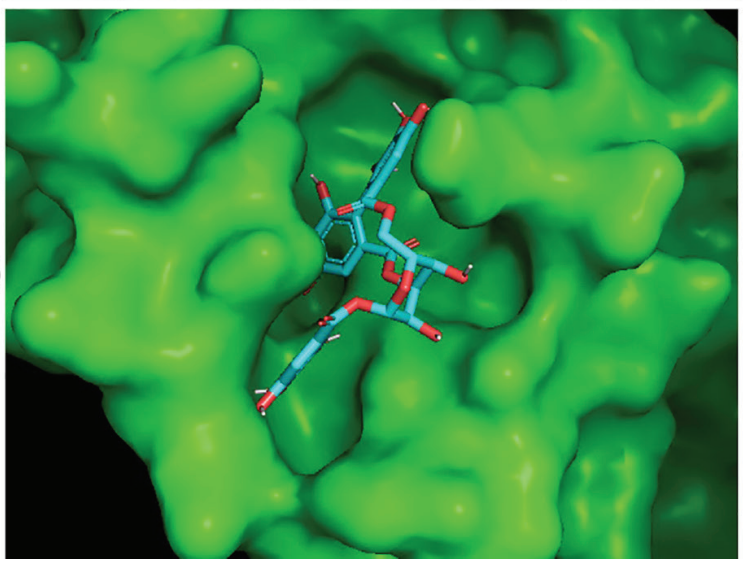

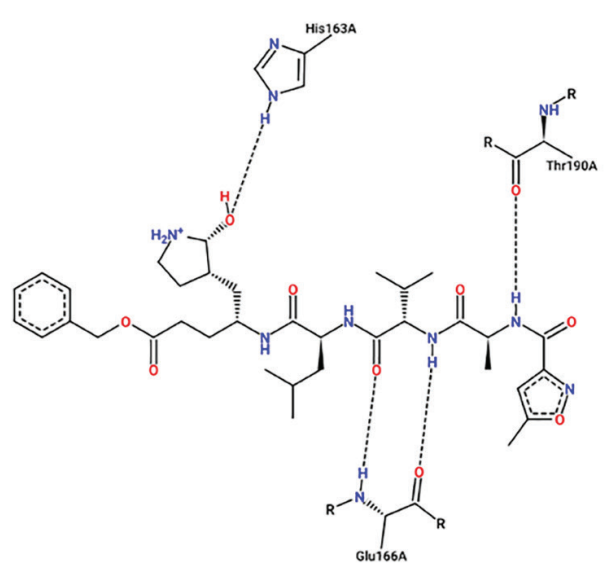
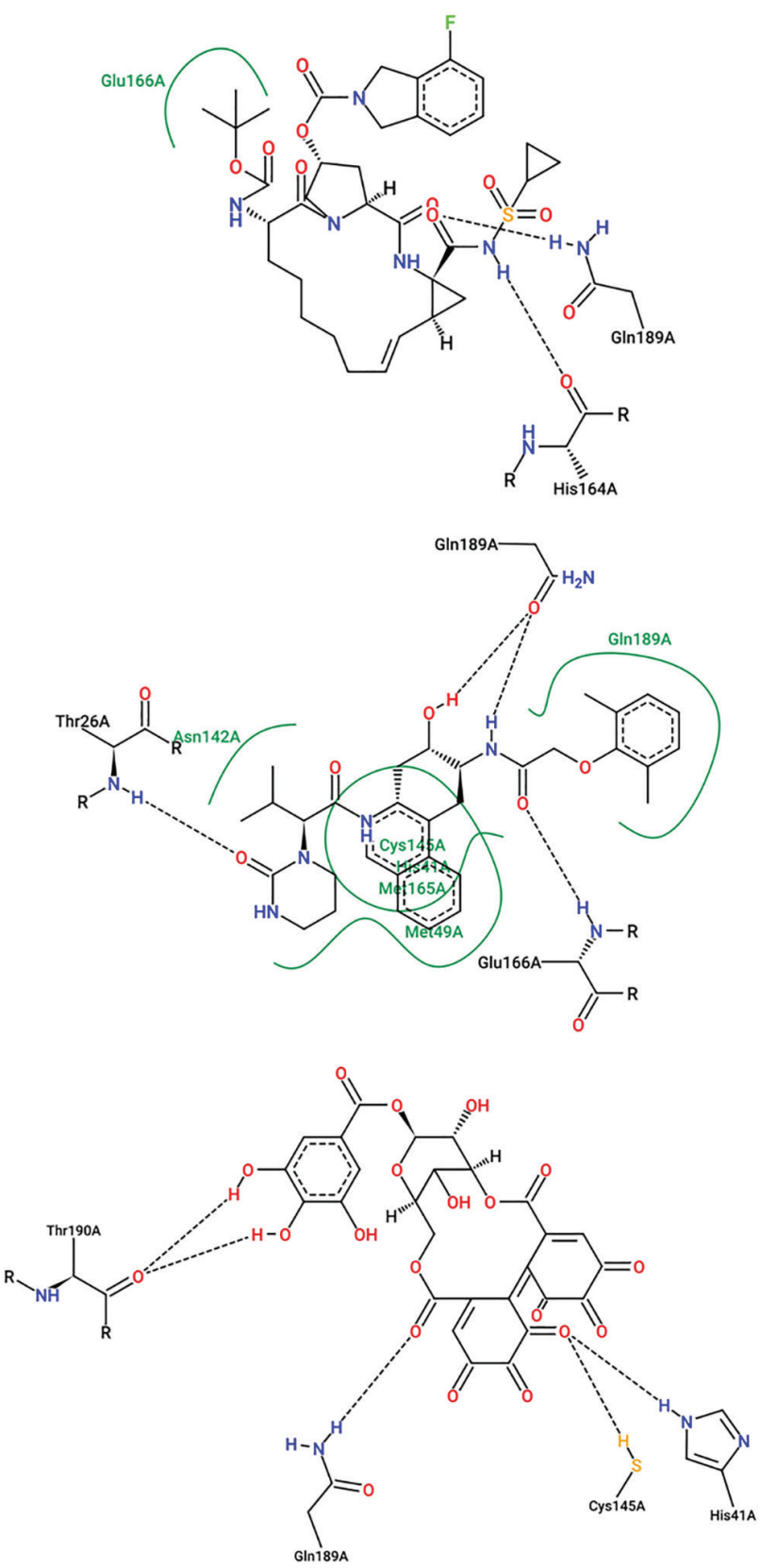

Figure 3. (a) Inhibitor 15; (b) danoprevir; (c) lopinavir; and (d) corilagin docked in the binding site of SARS-CoV-2 M ${ }^{\text {pro }}$. In (a), cyan is the co-crystallized structure; whereas red is the redocked pose. 
Table 2. Docking results: affinity energy and key binding site residues of SARS-CoV main protease

\begin{tabular}{|c|c|c|c|}
\hline Compound & Affinity / $\left(\mathrm{kcal} \mathrm{mol}^{-1}\right)$ & $\mathrm{H}$ bond & Hydrophobic \\
\hline Co-crystallized ligand & -9.8 & His-163, Glu-166, Thr-190 & \\
\hline \multicolumn{4}{|c|}{ Non-natural-HIV-1 protease inhibitors } \\
\hline Danoprevir & -8.5 & His-164, Gln-189 & Glu-166 \\
\hline Lopinavir & -8.5 & Thr-26, Glu-166, Gln-189 & His-41, Met-49, Asn-142, Cys-145, Met-165 \\
\hline Ritonavir & -7.9 & Ser-46, Gln-189 & His-41, Met-49, Cys-145, Met-165, Gln-189 \\
\hline Darunavir & -7.6 & Thr-25 & His-41, Met-49, Met-165, Gln-189 \\
\hline Oseltamivir & -6.0 & & \\
\hline \multicolumn{4}{|c|}{ HIV-1 protease inhibitors from plants } \\
\hline Corilagin & -8.2 & Cys-145, Gln-189, Thr-190 & \\
\hline Uvaol & -7.9 & Thr-24, Leu-141 & Thr-25, Met-49, Asn-142 \\
\hline Kaempferol & -7.8 & Leu-141, Asp-187, Gln-189 & Met-165, Gln-189 \\
\hline Oleanolic acid & -7.8 & Ser- 144 & Met-49, Cys-145, Gln-189 \\
\hline$\gamma$-Mangostin & -7.6 & Thr-190 & Met-165, Gln-189 \\
\hline$\alpha$-Mangostin & -7.4 & His-41, Thr-190 & Met-165, Gln-189 \\
\hline Rosmanol & -7.1 & Leu-141, Ser-144, Glu-166 & \\
\hline 7-O-Ethylrosmanol & -6.9 & & \\
\hline Carnosolic acid & -6.9 & Gly-143, Cys-145 & \\
\hline
\end{tabular}

HIV-1: human immunodeficiency virus type 1; His: histidine; Glu: glutamic acid; Thr: threonine; Gln: glutamine; Ser: serine; Cys: cysteine, Leu: leucine; Asp: aspartate; Gly: glycine; Met: methionine; Asn: asparagine.

As expected, the co-crystallized compound (15) presents the best affinity energy for that enzyme $\left(-9.8 \mathrm{kcal} \mathrm{mol}^{-1}\right)$. Comparing with that compound, two non-natural HIV-1 protease inhibitors, danoprevir (1) and lopinavir (3), showed the best affinity energy for the SARS-CoV-2 $\mathrm{M}^{\text {pro }}$ (-8.5 $\mathrm{kcal} \mathrm{mol}^{-1}$ ). Ritonavir (5), darunavir (2), and oseltamivir (4) showed affinity energies equal to -7.9 , -7.6 , and $-6.0 \mathrm{kcal} \mathrm{mol}^{-1}$, respectively. All HIV-1 protease inhibitors from plants showed better affinity energy for the SARS-CoV-2 Mpro than oseltamivir. Moreover, among those inhibitors, corilagin (7), a chemical isolated from Phyllanthus amarus, a plant known in Brazil as "quebrapedra", shows the best affinity energy for the enzyme; comparable to danoprevir (1) and lopinavir (3) affinities.

One remarkable finding regarding the simulations is the fact that no ligand-protease interacting pattern was found. The reason is the significant molecular diversity of the studied compounds. Figure 3 shows danoprevir, lopinavir, and corilagin docked into the SARS-CoV-2 Mro binding cavity. 2D-representations of the key interactions are also shown.

Table 2 shows that the ligands dock in the shallow binding site of SARS-CoV-2 $\mathrm{M}^{\text {pro }}$ through polar or hydrophobic interactions. A number of hydrogen bonds acts as "anchors" between carbonyl, hydroxyl, and amino groups of the compounds and the protease (Figure 3, and Supplementary Information section). Two compounds that showed the worst affinity values, oseltamivir and 7-O-ethylrosmanol, did not show significant interactions with the protease.

\section{Conclusions}

Since November 2019, the outbreak of COVID-19 infection has challenged the healthcare systems around the world, and several research approaches have been applied in order to try to identify potential new drugs. One of those strategies was the usage of non-natural HIV-1 protease inhibitors as probable candidates to treat the disease. In this context, one of the proposed hypothesis is the ability that such inhibitors would be able to inhibit the SARS-CoV-2 $\mathrm{M}^{\mathrm{pro}}$. Recently, the crystal structure of this specific CoV-2 enzyme was elucidated, and represents a good molecular target for designing new anti-CoV-2 drugs.

Following the line of thought regarding the usage of HIV-1 inhibitors as potential SARS-CoV-2 $\mathrm{M}^{\text {pro }}$ inhibitors, in this theoretical project it was verified the probability of some non-natural and natural HIV-1 protease inhibitors, selected from the literature, to be able to dock in the binding site of the SARS-CoV-2 $\mathrm{M}^{\text {pro }}$.

It was found that two non-natural compounds, danoprevir and lopinavir, and a compound isolated from Phyllanthus amarus, a plant known in Brazil as "quebrapedra", corilagin, bind strongly to the binding site of the 
protease of CoV-2. Consequently, although subsequent enzymatic experiments must be done, the docking results presented in this report support the hypothesis that perhaps danoprevir, lopinavir, and corilagin may be used as single antiviral agents targeting that enzyme or in combination with other potential therapies for treating COVID-19 patients.

\section{Supplementary Information}

Figures of compounds $2,5,6,8,9,10,11,12,14$ docked into the binding site of SARS-CoV-2 main protease is available free of charge at http://jbcs.sbq.org.br as PDF file.

\section{Acknowledgments}

The author is grateful to the Brazilian Ministries of Education, and of Science, Technology and Communication.

\section{References}

1. https://covid19.who.int/, accessed in June 2020.

2. Hui, D. S.; Azhar, E. I.; Madani, T. A.; Ntoumi, F.; Kock, R.; Dar, O.; Ippolito, G.; Mchugh, Z.; Memish, T. D.; Drosten, A.; Zumla, A.; Petersen, E.; Int. J. Infect. Dis. 2020, 91, 264.

3. Lu, H.; BioSci. Trends 2020, 14, 69.

4. https://www.genengnews.com/a-lists/how-to-conquercoronavirus-top-35-treatments-in-development, accessed in June 2020

5. Lin, L.-T.; Hsu, W.-C.; Lin, C.-C.; J. Tradit. Complementary Med. 2014, 4, 24.

6. Polya, G. M. In Studies in Natural Products Chemistry, vol. 29; Atta-ur-Rahman, ed.; Elsevier: Amsterdan, 2003, p. 567.
7. Paris, A.; Strukelj, B.; Renko, M.; Turk, V.; Pukl, M.; Umek, A.; Korant, B. D.; J. Nat. Prod. 1993, 56, 1426.

8. Xu, H. X.; Wan, M.; Dong, H.; But, P. P.; Foo, L. Y.; Biol. Pharm. Bull. 2000, 23, 1072.

9. Brinkworth, R. I.; Stoemer, M. J.; Fairlie, D. P.; Biochem. Biophys. Res. Commun. 1992, 188, 631.

10. Mahmood, N.; Piacente, S.; Pizza, C.; Burke, A.; Khan, A. I.; Hay, A. J.; Biochem. Biophys. Res. Commun. 1996, 229, 73.

11. Chen, S. X.; Wan, M.; Loh, B. N.; Planta Med. 1996, 62, 381.

12. Vlietinck, A. J.; De Bruyne, T.; Apers, S.; Pieters, L. A.; Planta Med. 1998, 64, 97

13. Ma, C.; Nakamura, N.; Hattori, M.; Kakuda, H.; Qiao, J.; Yu, H.; J. Nat. Prod. 2000, 63, 238.

14. Min, B. S.; Jung, H. J.; Lee, J. S.; Kim, Y. H.; Bok, S. H.; Ma, C. M.; Nakamura, N.; Hattori, M.; Bae, K. H.; Planta Med. 1999, 65, 374 .

15. Jin, Z.; Du, X.; Xu, Y.; Deng, Y.; Liu, M.; Zhao, Y.; Zhang, B.; Li, X.; Zhang, L.; Peng, C.; Duan, Y.; Yu, J.; Wang, L.; Yang, K.; Liu, F.; Jiang, R.; Yang, X.; You, T.; Liu, X.; Yang, X.; Bai, F.; Liu, H.; Liu, X.; Guddat, L. W.; Xu, W.; Xiao, G.; Qin, C.; Shi, Z.; Jiang, H.; Rao, Z.; Yang, H.; Nature 2020, 582, 289; http://www.rcsb.org/structure/6LU7, accessed in June 2020.

16. https://pubchem.ncbi.nlm.nih.gov, accessed in June 2020.

17. Rappe, A. K.; Casewit, C. J.; Colwell, K. S.; Goddard III, W. A.; Skiff, W. M.; J. Am. Chem. Soc. 1992, 114, 10024.

18. Trott, O.; Olson, A. J.; J. Comput. Chem. 2010, 31, 455.

19. Stierand, K.; Rarey, M.; Med. Chem. Lett. 2010, 1, 540.

20. The PyMOL Molecular Graphics System, version 2.1.0; Schrödinger, LLC., USA, 2018.

21. https://www.3dsbiovia.com/, accessed in June 2020.

Submitted: April 20, 2020

Published online: July 7, 2020 